
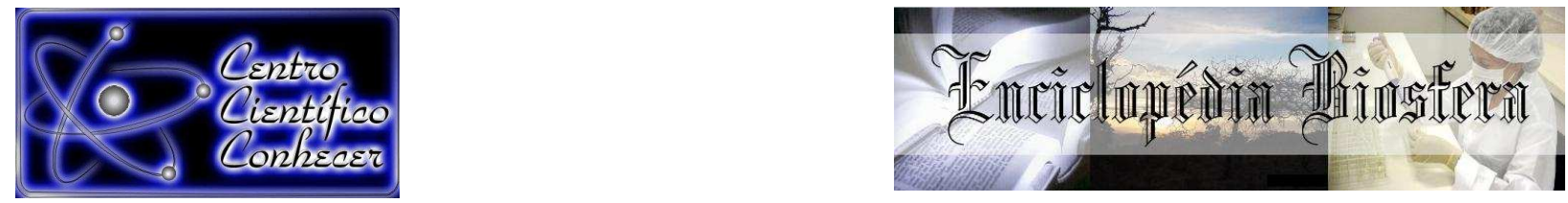

\title{
MORFOMETRIA DO TRATO GASTRINTESTINAL DE CODORNAS DE CORTE ALIMENTADAS COM DIETA A BASE DE SORGO GRÃO
}

\author{
Anna Gabriella Lima Saar ${ }^{1}$, Cíntia Amaral Moraes ${ }^{2}$, Evandro de Abreu Fernandes ${ }^{3}$, \\ Fernanda Heloisa Litz ${ }^{4}$, Luciana Ruggeri Menezes Gotardo ${ }^{5}$ \\ 1 - Médica Veterinária, Universidade Federal de Uberlândia, Uberlândia, Minas \\ Gerais, Brasil (gabiisaar@gmail.com) \\ 2 - Mestre em Ciências Veterinárias, Universidade Federal de Uberlândia, \\ Uberlândia, Minas Gerais, Brasil \\ 3 - Prof. Adjunto da Universidade Federal de Uberlândia, Campus Umuarama, \\ Uberlândia, Minas Gerais, Brasil \\ 4 - Doutoranda do programa de Pós-Graduação em Ciências Veterinárias, \\ Universidade Federal Uberlândia, Uberlândia, Minas Gerais, Brasil \\ 5 - Mestranda do programa de Pós-Graduação em Ciências Veterinárias, \\ Universidade Federal Uberlândia, Uberlândia, Minas Gerais, Brasil
}

\section{Recebido em: 08/09/2015 - Aprovado em: 14/11/2015 - Publicado em: 01/12/2015} DOI: http://dx.doi.org/10.18677/Enciclopedia_Biosfera_2015_199

\begin{abstract}
RESUMO
Objetivou-se com este trabalho comparar o desempenho de codornas alimentadas com rações à base de milho e à base de sorgo em diferentes proporções. Foram alojadas 1200 codornas japonesas, fêmeas de um dia de idade, dividas em 24 gaiolas, num delineamento inteiramente casualizado com quatro tipos de rações, seis repetições por tratamento e 50 aves cada. Os tratamentos foram divididos (A) $100 \%$ milho, (B) $60 \%$ milho - $40 \%$ sorgo e (c) $40 \%$ milho - $60 \%$ sorgo e (D) $100 \%$ sorgo. Este experimento comparou ao final de 42 dias, após o abate das aves, 0 tamanho $(\mathrm{cm})$ e peso absoluto $(\mathrm{g})$ dos intestinos delgado e grosso, fígado e moela, analisando $10 \%$ do total alojado. Os dados foram submetidos à ANOVA e as médias comparadas por teste de Tukey $(p>0,05)$. Não houve diferenças significativas entre 0 peso absoluto do fígado, moela e dos intestinos, assim como no tamanho $(\mathrm{cm})$ dos intestinos. Com estes resultados podemos constatar que o sorgo é um bom alimento na substituição total ou parcial do milho na alimentação de codornas de corte, sem comprometimento do trato gastrointestinal das mesmas.
\end{abstract}

PALAVRAS- CHAVE: Coturnix coturnix japônica, fígado, nutrição, sistema digestivo.

\section{MORPHOMETRY OF THE GASTROINTESTINAL TRACT OF QUAIL FED WITH GRAIN SORGHUM BASED DIETS}

\begin{abstract}
This study aimed to compare the performance of quail fed corn and sorghum at different proportions. In this experiment 1200 Japanese quail females from day one and the same, divided into 24 cages in a completely randomized design with four types of feed six replicates and 50 birds per experimental unit were housed. The four treatments were divided into A, B, C and D, being: (A) $100 \%$ corn, (B) $60 \%$ corn-
\end{abstract}


$40 \%$ sorghum; (C) $40 \%$ corn- $60 \%$ sorghum (D) $100 \%$ sorghum. Having as comparative size and weight of large and small intestines and liver weight and gizzard, analyzing $10 \%$ of the total housed. Data were analyzed by ANOVA and means were compared by Tukey test $(p>0.05)$. There were no significant differences between the absolute weight of the liver, gizzard and intestines, as well as the size (inches) from the intestines. With these results we can see that sorghum is a good food in total or partial replacement of corn in the diet of quail.

KEYWORDS: Coturnix coturnix japonica, digestive system, nutrition, liver.

\section{INTRODUÇÃO}

A coturnicultura de corte no Brasil, têm se tornado uma atividade altamente promissora devido à qualidade e ao valor nutricional da carne (alto conteúdo de proteína e baixo teor de gordura), porém pouco difundida nacionalmente (VELOSO et al., 2012).

Há outros fatores que chamam a atenção de alguns investidores, que podemos citar como: o baixo custo de produção inicial, rápido retorno financeiro, alta produtividade, rápido crescimento dos animais, precocidade na produção e a maturidade sexual (SILVA et al., 2010). Torna-se, dessa forma, uma das cadeias produtivas de ciclo mais rápido e de retorno garantido. No entanto, torna-se necessária a implantação de programas de melhoramento genético, que busquem desenvolver a evolução das características de importância econômica (TEIXEIRA et al, 2013).

Apesar de alguns aspectos organolépticos da carne de codorna ser distante da carne de frango, principalmente a cor que é escura, ela pode ser preparada de maneira semelhante a do frango de corte. Em se tratando do valor nutricional da carne de codorna, é uma excelente fonte de vitaminas, ácido pantotênico e também de ácidos graxos, além disso possui maiores teores de Ferro, Fósforo, Zinco, Cobre e aminoácidos do que a carne de frango (MORAES \& ARIKL, 2000).

A alimentação de codornas é feita empregando-se valores de energia metabolizável que, foram determinados com pintos, galos e galinhas poedeiras. Porém, essa base de dados pode considerada uma extrapolação incorreta, pois elas possuem maior taxa de passagem e maior proporção do aparelho digestivo em relação ao peso corporal. Portanto, diferenças na digestibilidade, no aproveitamento e na determinação do valor energético dos alimentos pode ocorrer (ARAUJO et al., 2011).

O milho e o farelo de soja se destacam na nutrição animal pela qualidade dos nutrientes e quantidade de inclusão nas dietas das rações formuladas para codornas. Porém, com a concorrência direta na utilização do milho para a alimentação humana e pela indústria de biocombustíveis para a produção do etanol, o preço tem se elevado no mercado internacional o que aumenta os custos de produção das aves. Assim, se explica o grande interesse de alguns pesquisadores a testarem ingredientes alternativos na formulação das dietas (CASARTELLI et al., 2005).

Um dos alimentos que veem sendo estudado para substituir o milho é o sorgo. MOURA et al (2010) mostraram que o custo do sorgo situa-se entre 70 e $80 \%$ do valor do milho e tecnicamente pode substituir até $100 \%$ do milho em rações, sem prejudicar o desempenho de codornas japonesas.

O grão vem se destacando nas pesquisas por suas características nutricionais e se destaca por apresentar melhor rendimento de nutrientes por 
unidade de área, principalmente nas regiões tropicais. Além disso, seu valor nutricional corresponde a $95 \%$ do milho e custa $88 \%$ do preço deste cereal, constituindo-se na mais promissora fonte de energia em substituição ao milho em rações para animais não-ruminantes (ROCHA et al., 2008).

Os estudos voltados à nutrição animal visam melhorias nos índices produtivos das aves tornando-se necessário estabelecer e atualizar constantemente os níveis adequados de nutrientes da dieta (BEZERRA et al., 2013). Alguns índices zootécnicos como: desempenho, consumo de ração, ganho de peso e conversão alimentar das aves nas fases iniciais e de crescimento, demonstram que a alta inclusão do sorgo e /ou a substituição por completo pelo milho resultam em números satisfatórios que atendem as metas dos produtores de aves (SILVA et al., 2009).

Além de monitorar e medir esses índices zootécnicos, pesquisas são desenvolvidas para observar e avaliar a resposta dos animais frente a alguns tratamentos, como por exemplo, diferentes rações. Uma delas é a pesagem dos órgãos que, geralmente é feita com o intuito de observar e avaliar a resposta do organismo do animal a certos tratamentos, já que esses órgãos podem apresentar uma hipo ou hipertrofia dependendo das condições nutricionais as quais são submetidos (GARCIA et al., 2005).

Este projeto de pesquisa buscou o conhecimento da morfometria do aparelho gastrointestinal (moela, fígado e intestinos) de codornas de corte estabelecendo um estudo comparativo dos quatros diferentes programas nutricionais, com inclusão de sorgo, atendendo todas as exigências nutricionais necessárias para um bom desempenho destas aves.

\section{MATERIAL E MÉTODOS}

Esta pesquisa foi realizada de acordo com Protocolo Registro CEUA/ UFU no 093/10. O experimento foi realizado na Universidade Federal de Uberlândia (UFU), Fazenda do Glória, na Granja de Pesquisa de Aves, sendo um galpão construído em alvenaria e estrutura metálica, com cobertura de telha de fibrocimento, piso concretado, paredes teladas, cortinas laterais, duplas (interna e externa), forrado com tecido plástico, nebulizadores e ventiladores. As aves foram criadas em 24 gaiolas $(0,50 \mathrm{~m} \times 0,80 \mathrm{~m})$, cada gaiola contendo um comedouro do tipo calha e um bebedouro copo de pressão, o ambiente foi aquecido no período inicial por infravermelho.

Foram alojadas 1200 codornas de um dia, 300 por tratamento, fêmeas e oriundas de aves de um mesmo lote de mesma idade, com 50 aves por gaiola. $O$ experimento foi inteiramente casualizado, com quatros tratamentos ( $A, B, C$ e D) e com seis repetições de cada, sendo eles; $(A)$ milho $100 \%$, (B) milho 60\%+ sorgo $40 \% \%$, (C) milho 40\% +sorgo 60\% e (D) sorgo 100\%. Realizou-se a debicagem nas aves aos 28 dias de idade, para evitar o canibalismo.

As aves foram alimentadas do $1^{\circ}$ ao $22^{\circ}$ dia com ração inicial e do $23^{\circ}$ ao $42^{\circ}$ com ração de crescimento. A ração foi fornecida à vontade, assim como a água. As rações foram produzidas à base de milho, milho e sorgo e sorgo com farelo de soja, óleo de soja, calcário, fosfato bicálcico, sal comum e premix vitamínico e mineral (Tabela 1 e 2). As rações foram formuladas com base nas tabelas brasileiras de aves e suínos para valores isoenergéticos e isonutrientes em cada fase (ROSTAGNO et al., 2011). 
TABELA 1- Composição da ração Inicial

\begin{tabular}{|c|c|c|c|c|}
\hline \multirow{2}{*}{ Ingredientes } & \multicolumn{4}{|c|}{ Tratamento } \\
\hline & $A$ & $B$ & C & $\mathrm{D}$ \\
\hline Milho grão 8.0 & 49,82 & 19,29 & 28,94 & 48,23 \\
\hline Sorgo 8.6 & 0,00 & 29,89 & 19,93 & 0,00 \\
\hline Soja Farelo $46,5 \%$ & 44,88 & 44,75 & 44,69 & 44,56 \\
\hline Óleo de Soja & 2,09 & 2,83 & 3,19 & 3,93 \\
\hline Calcário & 1,15 & 1,13 & 1,12 & 1,10 \\
\hline Fosfato bicalcico 18 & 0,97 & 1,01 & 1,03 & 1,07 \\
\hline Sal Comum & 0,49 & 0,49 & 0,50 & 0,50 \\
\hline PX INI FC SAA- MC & 0,40 & 0,40 & 0,40 & 0,40 \\
\hline DL- Metionina & 0,14 & 0,15 & 0,15 & 0,16 \\
\hline L- Treonina & 0,47 & 0,49 & 0,49 & 0,51 \\
\hline L- Lisina $\mathrm{HCl}$ & 0,00 & 0,00 & 0,00 & 0,00 \\
\hline \multicolumn{5}{|l|}{ Nutrientes } \\
\hline E.M (kcal/kg) & 2900 & 2900 & 2900 & 2900 \\
\hline Proteína Bruta & 25,00 & 25,00 & 25,00 & 25,00 \\
\hline Cálcio (\%) & 0,85 & 0,85 & 0,85 & 0,85 \\
\hline Fósforo disponível (\%) & 0,32 & 0,32 & 0,32 & 0,32 \\
\hline Sódio (\%) & 0,24 & 0,24 & 0,24 & 0,24 \\
\hline Metionina digestível & 0,48 & 0,48 & 0,484 & 0,49 \\
\hline M+Cistina digestível & 0,80 & 0,80 & 0,80 & 0,80 \\
\hline Treonina digestível (\%) & 0,89 & 0,89 & 0,89 & 0,89 \\
\hline Lisina digestível (\%) & 1,27 & 1,27 & 1,27 & 1,26 \\
\hline Valina digestível (\%) & 1,01 & 1,03 & 1,03 & 1,03 \\
\hline Triptofano digestível & 0,28 & 0,28 & 0,28 & 0,28 \\
\hline
\end{tabular}

Tratamentos (A) 100\% Milho; (B) 60\% Milho-40\%Sorgo; (C) 40\% Milho- 60\% Sorgo; (D) $100 \%$ Sorgo.

*Premix (composição por kg do produto): vit. A 2.000 .000 U.I., vit. D3 600.000 U.I., vit. E 3.500 $\mathrm{mg} / \mathrm{kg}$., vit. B1 $625 \mathrm{mg}$, vit. B2 1562,50 mg, vit. B6 $650 \mathrm{mg}$, biotina $15,65 \mathrm{mg}$, colina $104.125 \mathrm{mg}$, vit. K $458 \mathrm{mg}$, ác. fólico $250 \mathrm{mg}$, vit. B12 $2875 \mathrm{mg}$, selênio $78 \mathrm{mg}$, manganês $30.000 \mathrm{mg}$, ferro 12.500 $\mathrm{mg}$, zinco $20.000 \mathrm{mg}$, cobre $2.000 \mathrm{mg}$, iodo $187 \mathrm{mg}$

TABELA 2- Composição da Ração de Crescimento

\begin{tabular}{lcccc}
\hline \multirow{2}{*}{ Ingredientes } & \multicolumn{4}{c}{ Tratamento } \\
\cline { 2 - 5 } & $\mathrm{A}$ & $\mathrm{B}$ & $\mathrm{C}$ & $\mathrm{D}$ \\
\hline Milho grão 8.0 & 56,52 & 21,29 & 32,86 & 54,77 \\
Sorgo 8.6 & 0,00 & 33,91 & 22,61 & 0,00 \\
Soja Farelo 46,5\% & 37,35 & 37,17 & 37,09 & 36,91 \\
Óleo de Soja & 3,20 & 4,03 & 4,44 & 5,27 \\
Calcário & 1,00 & 0,98 & 0,96 & 0,94 \\
Fosfato bicalcico 18 & 0,90 & 0,94 & 0,96 & 1,00 \\
Sal Comum & 0,50 & 0,50 & 0,51 & 0,51 \\
PX INI FC SAA- MC & 0,40 & 0,40 & 0,40 & 0,40 \\
DL- Metionina & 0,13 & 0,13 & 0,14 & 0,14 \\
L- Treonina & 0,01 & 0,01 & 0,02 & 0,02 \\
L- Lisina HCl & 0,00 & 0,01 & 0,02 & 0,03 \\
\hline Nutrientes & & & & \\
\hline E.M (kcal/kg) & 3500 & 3500 & 3500 & 3500 \\
Proteína Bruta & 22,00 & 22,00 & 22,00 & 22,00
\end{tabular}




$\begin{array}{lllll}\text { Cálcio (\%) } & 0,75 & 0,75 & 0,75 & 0,75 \\ \text { Fosfóro disponível (\%) } & 0,30 & 0,30 & 0,30 & 0,30 \\ \text { Sódio (\%) } & 0,24 & 0,24 & 0,24 & 0,24 \\ \text { Metionina digestível } & 0,42 & 0,42 & 0,42 & 0,43 \\ \text { M+Cistina digestível } & 0,72 & 0,72 & 0,72 & 0,72 \\ \text { Treonina digestível (\%) } & 0,76 & 0,76 & 0,76 & 0,76 \\ \text { Lisina digestível (\%) } & 1,27 & 1,27 & 1,27 & 1,26 \\ \text { Valina digestível (\%) } & 1,08 & 1,08 & 1,08 & 1,08 \\ \text { Triptofano digestível } & 0,24 & 0,24 & 0,24 & 0,25\end{array}$

Tratamentos (A) 100\% Milho; (B) 60\% Milho-40\%Sorgo; (C) 40\% Milho- 60\% Sorgo; (D) $100 \%$ Sorgo.

*Premix (composição por kg do produto): vit. A 2.000 .000 U.I., vit. D3 600.000 U.I., vit. E 3.500 mg/kg., vit. B1 $625 \mathrm{mg}$, vit. B2 1562,50 mg, vit. B6 $650 \mathrm{mg}$, biotina 15,65 mg, colina $104.125 \mathrm{mg}$, vit. K $458 \mathrm{mg}$, ác. fólico $250 \mathrm{mg}$, vit. B12 $2875 \mathrm{mg}$, selênio $78 \mathrm{mg}$, manganês $30.000 \mathrm{mg}$, ferro 12.500 $\mathrm{mg}$, zinco $20.000 \mathrm{mg}$, cobre $2.000 \mathrm{mg}$, iodo $187 \mathrm{mg}$

Aos 42 dias, 120 aves, sendo 30 de cada tratamento foram sacrificadas por deslocamento cervical e posterior sangria, com uma tesoura cirúrgica foi feita incisão longitudinal no osso esterno, para exposição dos órgãos, sendo retirado o tubo gastrintestinal. Usando balança de precisão, o peso da moela foi registrado, após a retirada de todo conteúdo alimentar, assim como do fígado e dos intestinos. $O$ comprimento dos intestinos delgado e grosso foi determinado usando uma fita métrica com escala em centímetros.

Os dados foram submetidos à ANOVA e as médias comparadas por teste de Tukey, com nível de significância de 5\%.

\section{RESULTADOS E DISCUSSÃO}

Os resultados da morfometria do trato gastrintestinal não apresentaram diferença significativa ( $p>0,05)$, quando comparadas rações usando milho e sorgo (Tabela 3).

TABELA 3- Resultados médios do peso absoluto (g) do fígado, moela, intestinos grosso e delgado, e tamanho $(\mathrm{cm})$ dos intestinos grosso e delgado.

\begin{tabular}{ccccccc}
\hline \multirow{2}{*}{ Tratamento } & \multirow{2}{*}{$\begin{array}{c}\text { Peso } \\
\text { Fígado }(\mathrm{g})\end{array}$} & $\begin{array}{c}\text { Peso } \\
\text { Moela }(\mathrm{g})\end{array}$ & \multicolumn{2}{c}{ Intestino Grosso } & \multicolumn{2}{c}{ Intestino Delgado } \\
\cline { 5 - 7 } & & Peso $(\mathrm{g})$ & $\begin{array}{c}\text { Tamanho } \\
(\mathrm{cm})\end{array}$ & Peso $(\mathrm{g})$ & $\begin{array}{c}\text { Tamanho } \\
(\mathrm{cm})\end{array}$ \\
\hline A & 3,07 & 3,60 & 1,43 & 11,12 & 3,80 & 51,13 \\
B & 3,65 & 3,52 & 1,25 & 10,68 & 3,88 & 48,45 \\
C & 3,23 & 3,60 & 1,10 & 10,08 & 3,75 & 51,60 \\
D & 4,05 & 3,28 & 1,25 & 11,12 & 3,95 & 55,25 \\
\hline p-Valor & 0,40 & 0,56 & 0,46 & 0,21 & 0,96 & 0,07 \\
\hline
\end{tabular}

A: 100\% Milho; B: 60\% Milho- 40\% Sorgo; C: 40\% Milho-60\% Sorgo; D: 100\% Sorgo. *Médias seguidas de letras diferentes diferem entre si pelo teste de Tukey $5 \%$

Segundo pesquisas mais recentes, problemas no trato digestivo e dificuldade na digestibilidade de alguns nutrientes, que podem resultar na redução do desempenho das aves, deve-se a utilização de sorgo com alto tanino (GARCIA et 
al., 2005). Porém, no caso dessa pesquisa utilizou-se o sorgo que não contem tanino, podendo essa ser uma das causas da não diferenciação entre os tratamentos.

Uma alimentação com alto teor de fibras ou um aumento da granulometria das rações pode ter consequências como o aumento do peso da moela (LEANDRO et al., 2001). No presente experimento, não houve diferenciação nos níveis de fibra, nem alteração da granulometria entre os tratamentos, esta seria uma das explicações para não haver alteração da moela entre os tratamentos.

Avaliando o índice de gordura da moela e o peso relativo desse órgão, SILVA et al. (2010) obtiveram resultados que foram menores para as aves alimentadas com ração contendo 75 e $100 \%$ de substituição do milho pelo sorgo, respectivamente. Todavia, não encontraram na literatura, como o sorgo atua nesse órgão e na deposição de gordura nestas aves.

Experimento realizado por SAKAMOTO et al. (2006) com substituição do milho pelo sorgo nos níveis de 50 e $100 \%$ em rações para frangos de corte não houve alteração significativa para o consumo de ração, o ganho de peso, a conversão alimentar e pesos relativos do proventrículo, do pâncreas e do fígado.

Outro experimento de GARCIA et al. (2005) concluíram que, ao utilizar sorgo com alto tanino $(1,89 \mathrm{~g} / \mathrm{kg})$ e sorgo com baixo tanino $(0,49 \mathrm{~g} / \mathrm{kg})$ em substituição ao milho nas rações de frangos de corte não ocorrem alterações dos parâmetros de desempenho, rendimento de carcaça, porcentagem das vísceras e intestinos e medidas dos intestinos que possam comprometer tal substituição.

A utilização de sorgo na ração de frangos, segundo GARCIA et al. (2005), podem promover alterações na integridade da mucosa intestinal. A necrose na mucosa duodenal e erosões na superfície das mucosas foram observadas por alguns autores e a consequência é a redução da capacidade de absorção do trato gastrintestinal e do desempenho das aves.

Alterações no peso da moela de codornas japonesas alimentadas com rações de sorgo que substituíram com diferentes níveis o milho, também foi observada na pesquisa de ERMAMI (2012) e colaboradores, assim como neste estudo.

\section{CONCLUSÃO}

Com o presente trabalho podemos concluir que a substituição total ou parcial do milho pelo sorgo, não altera o desenvolvimento do trato gastrintestinal, sendo o sorgo um alimento alternativo na alimentação de codornas de corte.

\section{REFERÊNCIAS}

ARAUJO, M. S.; BARRETO, S. L. T.; GOMES, P. C. DONZELE, J. L.; BALBINO, E. M.; VALERIANO, M. H. Comparação de valores de energia metabolizável de alimentos determinados com frangos de corte e com codornas visando à formulação de dietas para codornas japonesas. Revista Brasileira de Zootecnia [online], v. 40, n. 2, p. 336-342, 2011.

BEZERRA, R. M.; FREITAS, E. R.; NASCIMENTO, G. A. J.; BRAZ, N. M.; FARIAS, N. N. P.; XAVIER, R. O. S. Níveis de cloro para codornas japonesas em crescimento e seus efeitos na fase de produção. Semina: Ciências Agrárias, Londrina, v. 34, n. 2, p. 853-862, 2013. 
CASARTELLI, E.M.; FILARDI, R.S.; JUNQUEIRA, O.M.; LAURENTIZ, A.C.;ASSUENA, V.; DUARTE, K.F. Commercial laying hen diets formulated according to different recommendations of total and digestible amino acids. Revista Brasileira de Ciência Avícola [sl], v. 7, n. 3, p. 177-180, 2005.

EMAMI, F., MAHERI-SIS, N., GHORBANI, A., VAHDATPOUR, T. Effects of replacing corn grain by reconstituted or um-reconstituted sorghum grain on carcass characteristics of Japanese quais (Coturnix coturnix japônica), International Journal of Biosciences, v. 2, n. 12, p. 90-96, 2012.

GARCIA, R. G.; MENDES, A. A.; ANDRADE, C.; PAZ, I. C. L. A., TAKAHASHI, S. E.; PELÍCIA, K.; KOMIYAMA, C. M.; QUINTEIRO, R. R. Avaliação do desempenho e de parâmetros gastrintestinais de frangos de corte alimentados com dietas formuladas com sorgo alto tanino e baixo tanino. Revista Ciência e Agrotecnologia, Lavras, v. 29, n. 6, p. 1248-1257, 2005.

LEANDRO, N.S.M.; STRINGHINI, J.H.; CAFÉ, M.B. Efeito da granulometria do milho e do farelo de soja sobre o desempenho de codornas japonesas. Revista Brasileira de Zootecnia [online], v. 30, n. 4, p. 1266-1271, 2001.

MORAES, V. M. B.; ARIKI J. Importância da nutrição na criação de codornas e qualidades nutricionais do ovo e carne de codorna - Universidade Estadual Paulista, Faculdade de Ciências Agrarias e Veterinárias, Departamento de Nutrição Animal, Jaboticabal, p.97-103, 2009.

MOURA, A. M. A.; FONSECA, J.B.; RABELLO, C. B.V.; TAKATA, F.N., OLIVEIRA, N. T. E. Desempenho e qualidade do ovo de codornas japonesas alimentadas com rações contendo sorgo. Revista Brasileira de Zootecnia [online], v. 39, n. 12, p. 2697-2702, 2011.

ROCHA, V. R. R. A.; JUNIOR, W. M. D.; RABELLO, C. B. V.; RAMALHO, R. P.; LUDKE, M. C. M. M.; SILVA, E. C. Substituição total do milho por sorgo e óleo de abatedouro avícola em dietas para frangos de corte. Revista Brasileira de Zootecnia [online], v. 37, n. 1, p. 95-102, 2008.

ROSTAGNO, H. S.; ALBINO, L. F. T.; DONZELE, J. L.; GOMES, P. C.; OLIVEIRA, R. F.; LOPES, D. C.; FERREIRA, A. S.; BARRETO, S. L. T.; EUCLIDES, R. F. Tabelas brasileiras para aves e suínos: composição de alimentos e exigências nutricionais. Viçosa: UFV-DZO, 2011. $252 \mathrm{p}$.

SAKAMOTO, M. I. MURAKAMI, A. E.; SOUZA, L. M. G.; FRANCO, J. R. G.; BRUNO, L. D. G.; FURLAN, A.C. Valor energético de alguns alimentos alternativos para codornas japonesas. Revista Brasileira de Zootecnia [online] vol. 35, n. 3, p. 818-821, 2006.

SILVA, J. D. T; DIAS, L. T. S.; MACHADO, C. R.; CARVALHO, M. R. B.; RIZZO, P. $\mathrm{V}$. Uso de sorgo com baixo teor em taninos na alimentação de frangos de corte. Nucleus Animalium, Maringá, v. 1, n. 2, p 1-14, 2010. 
SILVA, R. M.; FURLAN, A. C.; TON, A. P. S.; MARTINS, E. N.; SCHERER, C.; MURAKAMI, A. E. Exigências nutricionais de cálcio e fósforo de codornas de corte em crescimento. Revista Brasileira de Zootecnia [online] v. 38, n. 8, p. 1509-1517, 2009.

TEIXEIRA, B. B.; EUCLYDES, R. F.; TEIXEIRA, R. B.; SILVA, L. P.; TORRES, R. A.; SILVA, F. G.; LEHNER, H. G.; CAETANO, G. C. Herdabilidade de características de produção e postura em matrizes de codornas de corte. Ciência Rural, Santa Maria, v. 43, n. 2, 2013.

VELOSO, R. C.; PIRES, A. V.; TIMPANI, V. D.; DRUMOND, E. S. C.; GONÇALVEZ, F. M.; FILHO, D. E. F. Níveis de proteína bruta e energia metabolizável em uma linhagem de codorna de corte. Acta Scientiarum. Animal Sciences, Maringá, v. 34, n. 2, p. 169-174, 2012. 